\title{
FACTORS DETERMINING AUTHORS' WILLINGNESS TO WAIT FOR EDITORIAL DECISIONS FROM ECONOMIC HISTORY JOURNALS
}

\author{
Eline POELMANS \\ Sandra ROUSSEAU * \\ KU Leuven, Faculty of Economics and Business, \\ Warmoesberg 26, B-1000 Brussel \\ * Corresponding author: Sandra.rousseau@kuleuven.be; \\ phone: +32 260982 75; fax: +32 22176464
}

\section{Published as:}

Poelmans, E. and S. Rousseau (2015). Factors determining authors' willingness to wait for editorial decisions from economic history journals. Scientometrics, vol.102, p.1347-1374. doi: $10.1007 / \mathrm{s} 11192-014-1469-2$

\begin{abstract}
In this contribution, we measure how long researchers are willing to wait (WTW) for an editorial decision on the acceptance or rejection of a submitted manuscript. This measure serves as a proxy for the expected value of a publication to a researcher in the field of economic, business and financial history. We analyze how this WTW measure varies with the characteristics of the submitting authors themselves. We distinguish the impact of personal characteristics (including age, gender and geographic location) as well as work-related characteristics (including research discipline, affiliation and academic position). To identify the factors determining economic history authors' WTW for editorial decisions, we use a valuation technique known as stated choice experiments. Our results show that respondents found the standing of the journal to be at least as important as its ISI impact factor. Moreover, we find differences in publication culture between economic and history departments. Overall, researchers' willingness to wait is influenced to a greater extent by the research discipline in which the respondents are active (history versus economics), than by their personal characteristics (e.g. the education or the type of $\mathrm{PhD}$ they obtained)
\end{abstract}

Keywords: willingness-to-wait; manuscript submissions; economic history; stated choice experiments

JEL-codes: A12, C25 and N00 


\section{Introduction}

When authors choose a journal to submit a manuscript, the submission process is not only influenced by author and journal characteristics, but also by temporal factors. Doctoral students have to write their dissertation, and preferably publish at least one article, in four years. Researchers financed by projects face similar deadlines within the scope of their projects. Senior researchers are confronted with more requests (to collaborate, to write project proposals, to supervise students, etc...) than they can possibly meet within the available time frame. Submitting a manuscript to a journal of choice implies a sizable investment of time, i.e., time to make sure the manuscript fits with the journal's requirements, time to revise and adapt the manuscript according to referee suggestions and, most importantly, time to wait for a - hopefully positive - editorial decision. This being said, even if a manuscript has been rejected by a particular journal, the invested time is not completely lost, because often, referee comments can considerably improve the submitted paper.

Generally speaking, both journal editors and prospective authors are keen on reducing the time between the initial submission and final editorial decision. Therefore, in all disciplines publication delays have always been a concern to editors and submitting authors alike. Existing models of the publication-citation process (Egghe and Rousseau 2000; Yu et al. 2004) as a rule incorporate factors such as prolonged waiting times and other publication delays. It is often stated that one of the great advantages of the electronic age is a considerable reduction of the average time between manuscript submission and publication (Abt 1987; Schaffner 2002; Nicolas et al. 2006; Desjardins 2011). Nonetheless, researchers tend to carefully consider the most appropriate journal to submit their manuscript to. The choice to submit a paper to the most appropriate journal is often crucial, since academic job offers, promotions and tenure decisions tend to be based on researchers' publication and citation records (Conley et al. 2011). In our analysis, we measure how long researchers are willing to wait for an editorial decision on the acceptance or rejection of a submitted manuscript. This measure serves as a proxy for the expected value of a publication in that particular journal to a researcher. Thus this willingness to wait does not coincide with the time that researchers actually have to wait for an editorial decision. The willingness to wait and the actual waiting time are clearly different concepts. In this respect the willingness to wait can exceed the actual waiting time many times. The same difference applies when looking at price and value. A simple ring can have a price of 500 euro in the shop, but the value of that ring can greatly exceed the shop price for its owner. Price and value clearly measure different concepts.

The reasons for submitting a manuscript to a particular journal and the factors that drive this decision have been the subject of previous research. Gordon (1984) was one of the first to 
study these factors in the field of biochemistry. According to this author, manuscript submission decisions do not necessarily follow from a search for social recognition and peer approval, but rather from the perceived importance and standing of the selected journal. However, these results could not be readily generalized to other disciplines, as disciplines can vary significantly when it comes to the average acceptance or rejection rates of manuscripts and typical journals' characteristics (Becher 1994; Hicks 2004). Thus, the generalizability of Gordon's results has been tested for other fields. These follow-up studies include the work by Luukkonen (1992) for zoology, biomedicine as well as automation and control technology; the work by Frank (1994) for medicine; the research of Ziobrowski and Gibler (2000) in the field of real estate; the work of Cheung (2010) in the field of education; Søreide's and Winters' work (2010) on the surgical field and the work of Rousseau and Rousseau (2012) in the field of bibliometrics and information sciences.

In general, several factors drive authors' decisions to send their manuscript to a certain journal (see, for instance, Björk and Holmström 2006; Thompson 2007; Knight et al. 2008; Björk and Öörni 2009; Cheung 2010). These factors can be organized into two categories, namely author and journal characteristics. First, we consider author characteristics that play a role in submission decisions. Examples of these are the past submission and publication record of the author, age, gender, nationality, and the department of affiliation. Second, journal characteristics also matter. Examples include publication delays, rejection risks, author charges, journal prestige, and the quality of the review process; but also other research characteristics, such as the potential visibility of the paper in a particular journal and the impact on peers and practitioners. However, information on relevant journal characteristics, such as the acceptance rate or the delay time between submission and acceptance, is not easily available and this interferes with authors' submissions decisions (Björk and Öörni 2009).

In this contribution, we assess the impact of time constraints on the submitting author's willingness to wait (WTW) for a publication in a journal with specific characteristics in the field of 'economic, business and/or financial history' (in the remainder of the text 'economic history'). Researchers in this field come from at least two different disciplinary backgrounds. This may lead to a wide range of research approaches and practices in the field and also potentially other demands for tenure acquirement. This aspect adds the interesting dimension of studying a field at the intersection of two major social sciences, namely history and economics. Studies of authors' publication behavior in interdisciplinary fields are very scarce. In addition, we analyze how this WTW measure varies with the characteristics of the submitting authors themselves. We distinguish the impact of personal characteristics (including age, gender and geographic location) as well as work-related characteristics 
(including research discipline, affiliation and academic position). We use an economic valuation technique known as stated choice experiments (Louviere and Hensher 1982) to identify the factors determining economic history authors' WTW for editorial decisions. Stated choice experiments are an extensively used valuation technique in the social sciences for more than 20 years. They provide us with the opportunity to rank contributing factors and even to establish substitution rates between different factors in the authors' choice processes.

Our results show that respondents found the standing of the journal to be at least as important as its ISI impact factor. This crucial role of journal standing was also found within the field of the information sciences (Rousseau and Rousseau, 2012), but contrasts with the general feeling among academics that impact factors dominate all. Moreover, the effect of department affiliation on submission decisions dominates the effects of journal and other respondent characteristics, such as age or gender.

In the Methods section, we provide an overview of the choice experiment that we implemented as well as our survey design and characteristics. In the Results and Discussion section, we present our results for the respondent characteristics (personal characteristics, work related characteristics, and publication behavior), followed by our descriptive results, and the main effects of the different journal characteristics. We also identify the interaction effects between respondents' characteristics and submission preferences. Then, we compare willingness to wait with actual waiting times. The article ends with a concluding section.

\section{Methods}

In this section, we describe the methodology of stated choice experiments, the valuation method used to assess the contribution of each journal's characteristics to authors' decisions to submit a manuscript to a particular journal and the design of our questionnaire and survey.

\subsection{Stated choice experiments}

The method of stated choice experiments was developed by Louviere and Hensher (1982) and Louviere and Woodworth (1983). It is a survey-based method for modeling preferences for goods that are described in terms of their core characteristics and corresponding levels (Hanley et al. 2001). Choice experiments are used, among other disciplines, in marketing, psychology, transportation research, environmental economics, and health economics (Hanley et al. 2002; Amaya-Amaya et al. 2008; Kwak et al. 2010; Rousseau and Vranken 2013) for over twenty years. This technique is especially suited to accommodate multi-dimensional choices, such as the main choice in our study; the decision about where to submit a manuscript. Recently, Rousseau and Rousseau (2012) have used this method to investigate the manuscript submission process in the field of bibliometrics and information sciences. We now 
test whether these results carry over to another discipline. Therefore, we adapt the attributes and attributes levels used to describe the journals to reflect some important differences between these two disciplines.

Table 1. Example of a choice card

\begin{tabular}{|c|c|c|c|}
\hline & Journal A & Journal B & Back-up journal \\
\hline $\begin{array}{c}\text { Quality of editorial } \\
\text { board }\end{array}$ & Unknown & Unknown & Unknown \\
\hline $\begin{array}{l}\text { Quality of referee } \\
\text { reports }\end{array}$ & $\begin{array}{l}\text { High (useful } \\
\text { comments on style } \\
\text { and content) }\end{array}$ & $\begin{array}{l}\text { High (useful } \\
\text { comments on style } \\
\text { and content) }\end{array}$ & $\begin{array}{c}\text { Low } \\
\text { (not useful at all) }\end{array}$ \\
\hline $\begin{array}{c}\text { Probability of being } \\
\text { accepted }\end{array}$ & $\begin{array}{c}\text { High } \\
\text { (more than } 70 \% \text { ) }\end{array}$ & $\begin{array}{c}\text { Average } \\
\text { (between } 30 \text { and } \\
70 \% \text { ) }\end{array}$ & $\begin{array}{c}\text { High } \\
\text { (more than } 70 \% \text { ) }\end{array}$ \\
\hline ISI impact factor & $\begin{array}{l}\text { Low impact factor } \\
\quad(\text { less than } 1)\end{array}$ & $\begin{array}{l}\text { High impact factor } \\
\text { (more than } 1)\end{array}$ & No impact factor \\
\hline $\begin{array}{l}\text { Waiting time before } \\
\text { final decision (accept } \\
\text { or reject) }\end{array}$ & 6 months & 12 months & 3 months \\
\hline Standing among peers & High & High & Low \\
\hline Scope of the Journal & General history & General economics & $\begin{array}{l}\text { Eco., buss. and/or fin. } \\
\text { hist. }\end{array}$ \\
\hline
\end{tabular}

Stated choice experiments typically consist of different steps (Louviere et al. 2000). First, participants are asked to choose between three alternative varieties (option A, B or C) of a particular good - in this case a specific scientific journal - which differ through their corresponding levels of certain characteristics. In essence, they have to select their most preferred variety when choosing between A and B (see Table 1 for an example of such a choice set). In addition, a baseline alternative (option $\mathrm{C}$ ), reflecting the opt-out situation is included in each choice set, in order to be able to interpret the results in standard welfare economic terms. In this respect, choice experiments are typically used to ascertain the willingness-to-pay for each characteristic from peoples' choices by including price or cost as one of the characteristics of the good. In the current choice experiment, the price or cost characteristic was replaced by the waiting time $(3,6,12$ or 18 months) between manuscript submission and the final editorial decision on acceptance or rejection of the manuscript. By including the waiting time as a journal characteristic, we are able to ascertain the willingnessto-wait for each journal characteristic separately from respondents' choices (Rousseau and Rousseau 2012). Note that we extend the maximal waiting time from 9 to 18 months in order 
to reflect the longer actual waiting times in the field of economic history. For instance, as we discuss in more detail in section 4, the average time span between submission and acceptance in the Economic History Review was 18.94 months in 2010 and 2011.

The proposed journals in our choice experiment are hypothetical journals since this allows us to control combinations of different characteristics. We present the alternatives in the choice sets in a generic, unlabeled (alternatives A, B) form rather than a labeled form with actual journal names because we want the respondents to focus specifically on the attributes. An unlabeled experiment is preferred when the emphasis is on the marginal rates of substitution between attributes (Amaya-Amaya et al. 2008). On the other hand, an advantage of using labeled experiments is the familiarity with the context and hence the reduction in the cognitive burden. However, in a labeled design, respondents may use labeled alternatives to deduce information which they perceive as missing, particularly when researchers are familiar with some of the alternatives (de Bekker-Grob et al. 2010). This would then interfere with the statistical analysis of the results since we would not be able to correct for the, often implicit and varied, interpretations made by the respondents. In other words, if people already expect certain combinations of characteristics, it becomes difficult to estimate the impact of each journal characteristic separately. This problem of disentangling the individual effects of journal characteristics is addressed when we create hypothetical journals with strategically chosen combinations of characteristics. Moreover, the novelty bias when making choices in contingent (i.e. hypothetical) markets is minimal since we study a decision process that is well-known to the participants (List and Shogren 1999). Researchers are obviously familiar with the process of selecting a journal for submitting a paper and they are thus familiar with their own preferences in this regard. In addition, the combinations of characteristics we present to the respondents are sufficiently realistic since the actual journals in the field of economic history include quite a wide variety of characteristics. For instance, some journals have a high standing among researchers, but do not have an ISI impact factor.

In a second step, the preferences of the participants for certain journal characteristics are derived from respondents' answers. This analysis of the respondents' choices is based on random utility theory, which states that a respondent's utility function consists of a deterministic, observable component and a random, unobservable component $\varepsilon_{i}$ (Christie et al. 2004). In addition, the usual starting point is the assumption that the utility $U_{i}$ derived by an individual of choosing alternative $i$ can be approximated by a linear utility function of the form (Amaya-Amaya et al. 2008; Day et al. 2012):

$$
U_{i}=A S C_{i}+X_{i}^{\prime} \beta+\varepsilon_{i}
$$


where $X_{i}$ represents a M-dimensional vector of characteristic levels for alternative $i, \beta$ is a Mdimensional vector of coefficients capturing generic marginal (dis)utilities of characteristics and $A S C_{i}$ (Alternative Specific Constant) captures the main effect of the unobserved factors in the error terms for each of the alternatives.

In our study, the choice set $Z$ consists of three journal alternatives: variety $\mathrm{A}, \mathrm{B}$ and the optout option C. Choosing one alternative over the others implies that for the respondent, the utility of the chosen alternative exceeds the utility associated with the other alternatives. Thus, the probability of a participant choosing journal alternative $i$ from a particular choice set $Z$ can be expressed as:

$$
\begin{aligned}
& \operatorname{Pr}[i \mid Z]=\operatorname{Pr}\left[U_{i}>U_{j}\right], \forall j \neq i \in Z \\
& \operatorname{Pr}[i \mid Z]=\operatorname{Pr}\left[A S C_{i}+X_{i}^{\prime} \beta+\varepsilon_{i}>A S C_{j}+X_{j}^{\prime} \beta+\varepsilon_{j}\right]
\end{aligned}
$$

If we assume that the random terms in equation (1) are independently and identically distributed with an extreme value distribution, the choice probabilities defined in equation (2) have a closed-form solution known as the conditional logit model. ${ }^{1}$ Thus, we specify the observed utility $U_{n i t}$ of alternative $i$ for individual $n$ (from now on the subscript $n$ is omitted to simplify notation) in choice set $t$ as a linear function of the journal attributes $\left(X^{k}\right)$, including the waiting time $\left(X^{T}\right)$ :

$$
U_{i t}=\sum_{j} \beta_{j}^{C} A S C_{j}+\sum_{k}\left(\beta_{k}+\sum_{l} \alpha^{l} Z^{l}\right) X_{i t}^{k}+\beta_{T} X_{i t}^{T}+\varepsilon_{i t}
$$

Where the alternative specific constant $\left(A S C_{j}\right)$ is a dummy variable equal to 1 if $i=j$ and zero otherwise, $X^{k}$ is attribute $k$ and $X^{T}$ is a continuous variable expressing the waiting time in months. The variables $Z^{l}$ are socio-demographic characteristics that are made to interact with attribute variables in an attempt to partially explain the heterogeneity of respondents' preferences. We will estimate two models, one without ('main effects' model) and another with ('interaction' model) socio-demographic variables $Z^{l}$ included in the utility function.

Based on this specification, the marginal willingness-to-wait (WTW) for a change in one specific characteristic $k$ can be estimated as a ratio of the estimated coefficient for that characteristic $\left(\beta_{k}\right)$ and the estimated coefficient for the waiting time variable $\left(\beta_{T}\right)$ :

$$
W T W=-\frac{\beta_{k}}{\beta_{T}}
$$

For more information on the mathematical and statistical details of this method, we refer to Alberini et al. (2006) and Amaya-Amaya et al. (2008).

\footnotetext{
${ }^{1}$ When the error terms are not independently and identically distributed, a mixed logit model or a latent class model is used to estimate the choice probabilities (see, e.g., Alberini et al. 2006).
} 


\subsection{Survey design}

In our study, participants had to complete a questionnaire that consisted of two parts. The first part dealt with socio-demographic questions and variables - including nationality, age, gender, affiliation, discipline of obtained degrees, research discipline and current employment - as well as questions relating to the respondents' current submission practices such as: their preferred research outlet, the number of papers they submitted and/or published in the past two years, their estimate about the probability that a submitted manuscript would be accepted for publication, their motivation for publishing and journal selection strategies.

The second part of our questionnaire was the actual choice experiment, which consisted of a series of choices between two journal varieties and an opt-out option. The design of the choice experiment was developed in several steps. First, the good of interest was determined as the choice process of researchers when they select a journal for manuscript submission. Second, the (hypothetical) journals had to be identified in terms of their main characteristics. Based on pre-tests, survey results reported by Leyman et al. (2011), and previous research by Rousseau and Rousseau (2012), we selected the following characteristics: the quality of the editorial board, the quality of the referee reports, the probability of being accepted, the ISI impact factor, the waiting time before final decision about acceptance or rejection of the submitted paper, the journal's standing and reputation among peers, and its scope (general history, general economics or economic, business and financial history). Note that we added 'scope' as a journal attribute compared to Rousseau and Rousseau (2012), since we are studying a discipline balancing between economics and history. Third, the relevant levels had to be determined for each of these characteristics. In Table 2, the different levels for each characteristic as well as the variable names used later in the estimations are shown.

We select the ISI impact factor as the attribute to represent the impact of a journal because this is overall the best known indicator among researchers. For example, Leyman et al. (2011) performed a survey among all senior researchers in Flanders (Belgium) and 81.6\% of their respondents from social sciences mentions that having journal articles covered in the Web of Science is an important measure in their field. In addition, this study found that the impact factor of a journal strongly influenced the selection of a journal for submitting a manuscript for $82 \%$ of the respondents from social sciences. This dominance of the ISI impact factor can to a large extent be explained by its role in funding, recruitment and promotion decisions (Weingart, 2005). We selected a threshold value of 1 for the impact factor attribute, since this represents the $90^{\text {th }}$ percentile when we rank the 33 different journals in the field 'History of social sciences' according to their 2012 ISI impact factor. Despite its popularity, the ISI impact factor has been frequently and extensively criticized. The problems with this indicator 
include, among other things, the following issues (Rousseau, 2002; Moed, 2005; Stock, 2009; Waltman et al., 2011): not all academic journals are indexed by the Web of Science; the definition of a 'citable' publication is unclear; not all fields, regions and languages are treated in the same way; impact factors can be manipulated by journal editors; impact factors do not take discipline-specific citation patterns into account; and the dataset itself is not error-free. To address one or more of these issues alternative journal quality indicators have emerged. Thomson Reuters now also reports measures such as the 5-year synchronous impact factor, the Eigenfactor score and the Article Influence Score (AIS) in their Journal Citation Reports. Elsevier has created an alternative database Scopus with a broader coverage than the Web of Science and reports measures such as the SNIP indicator (Source Normalized Impact per Paper). The Scopus database has further been used to create an alternative journal ranking, namely the SCImago journal rank (SJR). The SJR as well as the Eigenfactor score and the AIS are based on the Pinsky-Narin approach (Pinsky and Narin, 1976) which weighs citations by the impact of the citing journal.

Table 2. Characteristics and their levels

\begin{tabular}{|ll|}
\hline Characteristic & Characteristic levels (dummy variable name) \\
\hline Quality of the editorial board & Unknown \\
& Highly regarded editors (higheditor) \\
\hline Probability of being accepted & Low - not useful at all \\
& Average - useful comments on style (medref) \\
& High - useful comments on style and content (highref) \\
\hline ISI impact factor & Low - less than 30\% (lowprobacc) \\
& Average - between 30\% and 70\% (medprobacc) \\
& High - more than 70\% \\
\hline Waiting time before final decision: & No impact factor \\
& Low impact factor - less than 1 (lowimpact) \\
& High impact factor - more than 1 (highimpact) \\
\hline accept/reject & 6 month \\
& 12 months \\
& 18 months \\
\hline Standing of the journal among peers & Low \\
& Average (medstand) \\
& High (highstand) \\
\hline Scope of the journal & General History (histscope) \\
& General Economics (econscope) \\
& Economic, business and/or financial history \\
&
\end{tabular}

Fourth, it had to be decided which specific combinations of journal characteristics would be selected for and included in the choice experiment. In this respect, a complete enumeration of all possible journal varieties based on all different combinations of the characteristic levels in Table 1 yields 2.3.3.3.4.3.3 = 1944 different possible journal varieties. However, we have to limit the number of possible varieties included in our questionnaire so as to keep the number 
of choices made by each respondent manageable. The strategy to select a limited number of journal varieties is based on an orthogonal main effects plan (OMEP), which allows for an uncorrelated estimation of all main effects, under the assumption that all interactions between characteristics are negligible (Street et al. 2005). Thus, using SPSS, we determined an OMEP which included 18 different journal varieties. These 18 journal varieties were randomly paired to construct 9 different choice sets. The 9 different choice sets were randomly presented to each respondent in order to minimize the impact of possible learning and fatigue effects ${ }^{2}$. A recent and extensive study of ordering effects in stated preference methods can be found in Day et al. (2012). Fifth, the selected journal varieties had to be incorporated into choice sets and the opt-out option (option C) had to be determined. In this respect, each choice set consisted of two different journal varieties and a back-up journal, and an example of a choice set is presented in Table 1. In our experiment the back-up journal represented a convenient, low quality journal to which a paper could always be sent. The following set of characteristics identify this low quality journal: an unknown quality of the editorial board, a low quality of the referee reports, a high probability of being accepted, no impact factor, the waiting time before a final decision is made is (only) three months, a low standing among peers and the scope of the journal is economic, business and financial history.

\subsection{Survey characteristics}

In this section, we present the actual implementation of the survey and discuss the sample selection and response rates.

We selected a representative sample of researchers in the field of economic, business and/or financial history. In order to do this, we compiled a list of all authors that published in 2010 and/or 2011 in five randomly selected journals from the top twenty journals in the field (ISI subject category 'History of Social Sciences') - no. 1, 2, 6, 18 and 20, according to their 2011 impact factors (Table 3) - and who had included their email address in the published manuscript or whose email-addresses could be found on the internet. Scholars that were working in the field of economic history, according to NEP-his ${ }^{3}$, were then added. Also, scholars that attended at least one of the six yearly conferences in the field - conferences of the Association of Business Historians $(\mathrm{ABH})$, the Economic and Business History Society (EBHS), the Economic History Association (EHA), the Economic History Society (EHS), the

\footnotetext{
${ }^{2}$ Learning and fatigue effects are instances of order effects. Learning effects occur when initially confused respondents make choices that are more closely aligned with their preferences when they become more familiar with the task format. Fatigue effects follow when respondents' motivation to carefully consider their preferences decreases due to growing fatigue as a result of the cognitive burden of processing repeated choice tasks. Fatigued respondents may, for example, begin to exhibit greater randomness in their choices (see, e.g., Day et al. 2012).

3 "This list attempts to categories authors by fields. The procedure is to look at all their papers announced in a NEP report. If more than 5 or $25 \%$ have appeared in a report, authors are considered to be working within that field. Note that a paper may appear in several reports." See: $\underline{\text { http://ideas.repec.org/i/ehis.html. }}$
} 
European Association for Banking and Financial History (EABH) and the European Business History Association (EBHA) - in 2010 and/or 2011 were included. After removing duplicates, we obtained a list of approximately 1200 'distinct' email addresses. If possible (if we could link different email addresses to the same person), we therefore counted all different email addresses belonging to the same individual researcher as one 'distinct' email address. Because of our specific data gathering procedure, most researchers that we sent our questionnaire to were actually working in the field of economic history (in the broad sense). However, some were clearly not directly working in this field - but mostly working on purely economic or history related topics - although they all had expressed an interest in the field of economic history as was evident by their publication record or by their presence at the above-mentioned conferences. The survey was executed online and respondents were invited by e-mail (on 22 April 2012) to fill in the questionnaire.

Table 3. Sample selection (subject category 'History of Social Sciences')

\begin{tabular}{|c|c|c|c|c|c|c|c|}
\hline Journal & \multicolumn{2}{|c|}{$2012 \mathrm{IF}$} & \multicolumn{2}{|c|}{$2011 \mathrm{IF}$} & \multicolumn{2}{|c|}{$2010 \mathrm{IF}$} & $\begin{array}{c}\text { 5-year IF } \\
(2007-2011)\end{array}$ \\
\hline $\begin{array}{l}\text { European Review of } \\
\text { Economic History }\end{array}$ & 2 & $(1.206)$ & 6 & $(0.774)$ & 9 & $(0.594)$ & I \\
\hline $\begin{array}{l}\text { The Journal of Economic } \\
\text { History }\end{array}$ & 5 & $(0.766)$ & 1 & $(1.015)$ & 2 & $(1.042)$ & $1 \quad(1.120)$ \\
\hline $\begin{array}{l}\text { Explorations in Economic } \\
\text { History }\end{array}$ & 8 & $(0.686)$ & 2 & $(0.935)$ & 1 & $(1.222)$ & $3 \quad(0.898)$ \\
\hline Business History & 15 & $(0.474)$ & 18 & $(0.345)$ & 13 & $(0.427)$ & $11(0.557)$ \\
\hline Enterprise \& Society & 24 & $(0.233)$ & 20 & $(0.312)$ & 18 & $(0.306)$ & $10(0.560)$ \\
\hline
\end{tabular}

Source: Thomson Reuters' Social Sciences citation Index (ISI)

The input of survey data from novel respondents was stopped on 10 June 2012. Of the 1200 distinct email addresses that we sent our survey to, 45 addresses were no longer in use. In total, we received 332 responses of which 224 were fully completed, with the remaining 108 being only partially completed. Thus we have a response rate of $332 /(1200-45)=28.74 \%$ (or $19.39 \%$ if only the fully completed questionnaires are considered), which is high for an online questionnaire/survey. Indeed, Saunders et al. (2011) mention a typical response rate of only $11 \%$ for internet surveys, which increases to $30 \%$ for online surveys which are conducted within a specific company.

\section{Results and discussion}

In this section, we present the following descriptive characteristics of the respondents' sample (respondent characteristics): personal characteristics, work-related characteristics and the respondents' publication behavior. Next, we present a descriptive analysis of the respondents' reasons for publishing, their journal selection strategies and the preferred research outlet of 
both the individual respondent and his/her institution. In addition, we present and discuss our main effects results, which we have identified by using a conditional logit model to estimate the probability that a particular journal variety was chosen by the respondents. This estimation further allows us to calculate the respondents' willingness-to-wait for different journal characteristics. Then, we present and discuss the interaction effects between journals' characteristics and respondents' characteristics. Finally, all the respondents that have taken less than two minutes to fill in the questionnaire (a time span that is not even enough to just read the questionnaire, let alone provide acceptable answers) were removed from the dataset.

\subsection{Respondent characteristics}

The survey was completely anonymous, so we do not know the names of the respondents who filled in the questionnaire and those who did not. Still, based on the email addresses, we were able to look at the geographical and gender distribution of all researchers ${ }^{4}$ that were contacted.

\subsubsection{Personal characteristics}

A majority of the respondents was male (71\%), all age categories were represented in the sample - with the vast majority aged between 26 and 55 - and the great majority of the respondents had a doctoral degree (85\%), of whom $49 \%$ had a Ph.D. in economics, $23 \%$ in economic, business and/or financial history, $21 \%$ in other fields of history, and $7 \%$ in other disciplines. As for the country of their current affiliation, $69 \%$ of the respondents were working in Europe (including Russia), followed by North America (21\%). The numbers of researchers from Asia (including Turkey) (5\%), Central and South America (4\%) and Africa and Oceania (less than 1\%) were considerably smaller (Table 4).

Table 4. Personal sample characteristics (in \% respondents in sample)

\begin{tabular}{|lc|lc|}
\hline Age category & & Continent & \\
$<26$ years & $2 \%$ & Europe (including Russia) & $69 \%$ \\
$26-35$ years & $28 \%$ & North America & $21 \%$ \\
$36-45$ years & $24 \%$ & Central and South America & $4 \%$ \\
$46-55$ years & $29 \%$ & Asia (including Turkey) & $5 \%$ \\
$56-65$ years & $12 \%$ & Africa and Oceania & $<1 \%$ \\
$>65$ years & $5 \%$ & & \\
\hline Gender & & Doctoral degree & $15 \%$ \\
Male & No & Yes & $85 \%$ \\
Female & $71 \%$ & Type of doctoral degree* & \\
& $29 \%$ & In economics & $49 \%$ \\
& & In history & $21 \%$ \\
& & In economic, business and/ or financial history & $23 \%$ \\
& & Other & $7 \%$ \\
\hline
\end{tabular}

* More than one doctoral degree per respondent is possible.

\footnotetext{
${ }^{4}$ Some email addresses $(15.3 \%)$ such as gmail-addresses could not be linked to a specific continent and based on the NEP-HIS list some first names (1.3\%) could be used for both male and female.
} 
Comparing the respondents with all contacted researchers, we find that relatively more females answered the questionnaire (29\% in respondent sample versus $19 \%$ in contacted sample). In addition, relatively more European than North-American researchers participated in the survey (69\% Europeans and 21\% North-Americans in respondent sample versus 56\% Europeans and $32 \%$ North-Americans in contacted sample).

\subsubsection{Work-related characteristics}

Because our respondents were selected to be working within a well-defined discipline, namely economic history, it is not surprising that $54 \%$ of the respondents indicated that the majority of their research was situated within the field of economic history. In addition, $28 \%$ of the respondents indicated they were working purely in economics, $11 \%$ were working purely in history, with another 7\% predominantly working in other social sciences (4\%) and other sciences (3\%). Nevertheless, given our selection criteria (see above) all respondents had published in economic, business and/or financial history journals and/or had at least shown some interest by attending conferences in this field (Table 5).

We were also interested in the employment situation of the respondents: $62 \%$ indicated that they had a permanent contract and were not actively seeking for a new position in another institution in the next two years. Approximately $10 \%$ of the respondents had a permanent contract, but were nonetheless seeking a new position in another institution in the next two years. The remaining $28 \%$ of respondents had a temporary contract, with $16 \%$ actively looking for a new position in another institution within the next two years (Table 5).

Regarding their current (academic) position, 81\% of the respondents were either full professor (28\%), or had another type of faculty position (assistant or associate professor, lecturer, etc.) (53\%). The remaining $18 \%$ had research positions (research assistant, doctoral candidate or postdoc), with the final $1 \%$ of respondents falling into the 'other' category (including retired professors, other researchers and grad students). Most respondents (81\%) were affiliated with a university, whereas $11 \%$ was affiliated with a research center, $6 \%$ with a business school and another $4 \%$ with a museum, library or archive. Researchers could indicate more than one affiliation. Looking at those affiliated with a university, $66 \%$ belonged to an economics department, $19 \%$ to a history department and $5 \%$ to an economic history department. In our opinion, the low number of respondents affiliated with an economic history department (only $5 \%$ ) can be largely explained by the fact that in most universities, no separate department of economic history exists, and that 'economic history' is organized as a working group within the economics and/or history departments (Table 5). 
Table 5. Work related sample characteristics (in \% respondents in sample)

Scientific discipline of majority of research

$\begin{array}{ll}\text { Economics } & 28 \%\end{array}$

History $\quad 11 \%$

Total of economic, business and financial history $\quad 54 \%$

$\begin{array}{ll}\text { Economic history } & 29 \%\end{array}$

Business history $\quad 9 \%$

$\begin{array}{ll}\text { Financial history } & 6 \%\end{array}$

Economic, business and financial history $10 \%$

Other social sciences (excl. economics and history) $\quad 4 \%$

Other $\quad 3 \%$

Current employment situation

Permanent contract and:

-not actively seeking for new position in another institution within next 2 years $\quad 62 \%$

-actively seeking for new position in another institution within next 2 years $\quad 10 \%$

Temporary contract and:

-not actively seeking for new position in another institution within next 2 years $\quad 12 \%$

-actively seeking for new position in another institution within next 2 years $16 \%$

Current (academic) position

Researcher (assistant, doctoral, postdoc) $\quad 18 \%$

Other type of faculty position (assistant/associate professor, (senior) lecturer, etc.) $\quad 53 \%$

$\begin{array}{ll}\text { Full professor } & 28 \%\end{array}$

Other (grad student, other type of researcher, retired professor, etc.)

\begin{tabular}{l|l} 
Current affiliation* & University department of current affiliation*
\end{tabular}

University $\quad 81 \%$

Research center $\quad 11 \%$

Business School $\quad 6 \%$

Museum, library or archive $\quad 4 \%$

Government $\quad 2 \%$

International Institution $\quad 2 \%$

Consultancy firm $2 \%$

Bank $2 \%$

Other affiliations

Economics department $\quad 66 \%$

History department $\quad 19 \%$

Economic history department $\quad 5 \%$

Sociology or political sciences $\quad 3 \%$

Other $\quad 7 \%$

\subsubsection{Publication behavior of respondents}

As shown in table 6,14\% of the respondents did not publish at all in the past two years, while $2 \%$ published more than ten papers. Most respondents (54\%) published between 2 and 5 papers in 2010 and 2011. In addition, we asked respondents to estimate the probability, based on their past experiences, that their paper would be accepted for publication by a particular journal. We found that $18 \%$ of respondents indicated that the expected probability of their paper being accepted was above $70 \%$, while $45 \%$ indicated that this probability was between 50 and $70 \%$. The reported estimate of the probability of acceptance was positively correlated ( $95 \%$ statistical significance) with the age of the researcher, the current rank of the researcher, and the number of previous publications. 
Table 6. Publication behavior of respondents.

\begin{tabular}{|c|c|c|c|}
\hline $\begin{array}{l}\text { Number of publications and } \\
\text { accepted papers in } 2010 \text { and } \\
2011\end{array}$ & $\begin{array}{l}\% \text { of } \\
\text { respondents in } \\
\text { sample }\end{array}$ & $\begin{array}{l}\text { Estimated probability of a paper } \\
\text { being accepted for publication by a } \\
\text { particular journal* }\end{array}$ & $\begin{array}{l}\% \text { of } \\
\text { respondents } \\
\text { in sample }\end{array}$ \\
\hline No papers & $14 \%$ & Less than $10 \%$ & $4 \%$ \\
\hline One paper & $17 \%$ & Between $10 \%$ and $30 \%$ & $23 \%$ \\
\hline Between 2 and 5 papers & $54 \%$ & Between $30 \%$ and $50 \%$ & $28 \%$ \\
\hline Between 5 and 10 papers & $13 \%$ & Between $50 \%$ and $70 \%$ & $27 \%$ \\
\hline More than 10 papers & $2 \%$ & More than $70 \%$ & $18 \%$ \\
\hline
\end{tabular}

*This probability is estimated as an average over all individual submissions over all journal types.

\subsection{Descriptive analysis}

In this section, we look at the reasons why respondents want to publish and how they select journals.

\subsubsection{Reasons for publishing}

Respondents were asked to select a maximum of three reasons why they would want to publish their work (Figure 1). Researchers in economic history do not seem to be driven by monetary rewards, but instead value their standing among peers. The two most selected reasons were the 'distribution of research findings' and 'to contribute to scientific progress in their discipline', followed by 'improving their standing among their peers' and - to a lesser extent - 'increasing their chances of getting promoted' (Figure 1).

\section{Figure 1. Reasons for publishing}

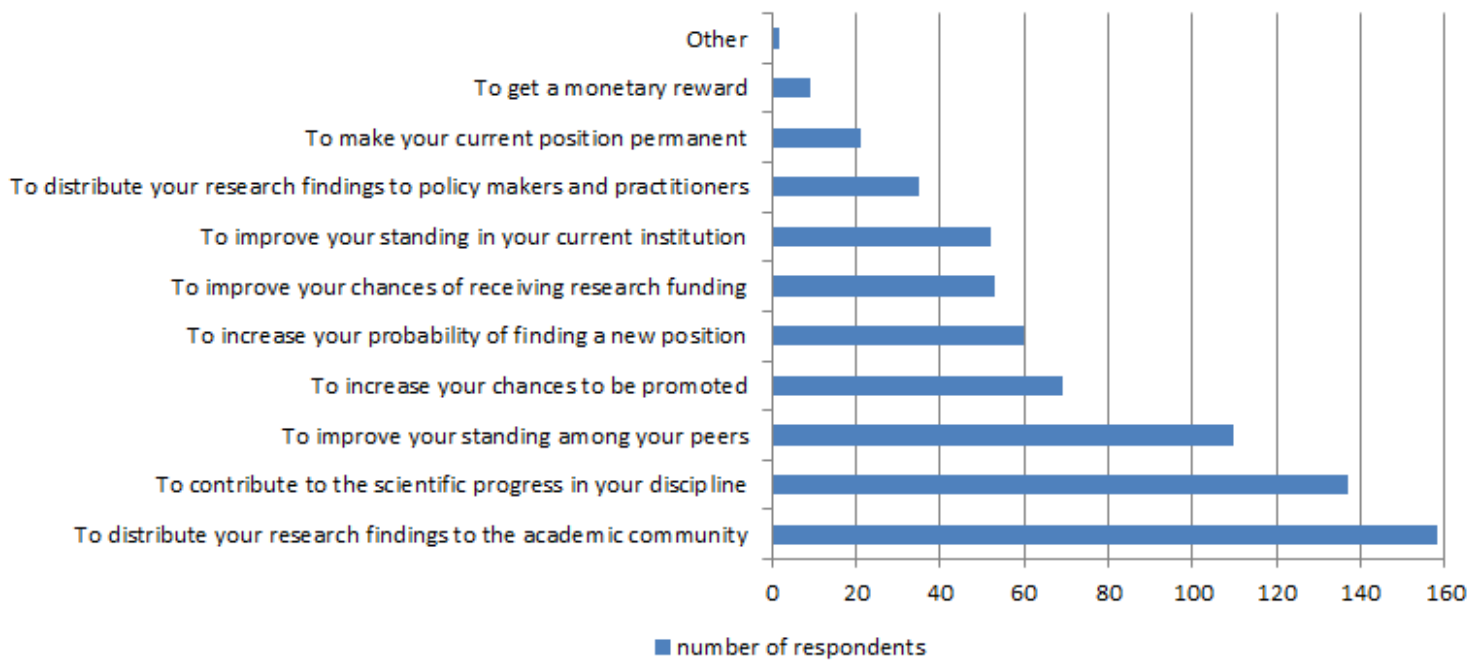

\subsubsection{Journal selection strategies}

Subsequently we asked respondents which three journal characteristics they considered to be the most important when selecting a journal to submit their paper to (Figure 2). It is somewhat surprising to see that apparently, the respondents found the 'general standing of the journal' to be more important than its 'ISI impact factor'. However, this result is in line with the result 
obtained in Rousseau and Rousseau (2012) for the field of the information sciences. The fact that over half of the respondents were in a permanent position and were not actively searching for a new position in the short term may play a role too. The 'quality of the paper', the 'probability of acceptance' and the 'scope of the journal' were also deemed to be important factors in the selection of a particular journal (Figure 2).

Figure 2. Journal selection strategies.

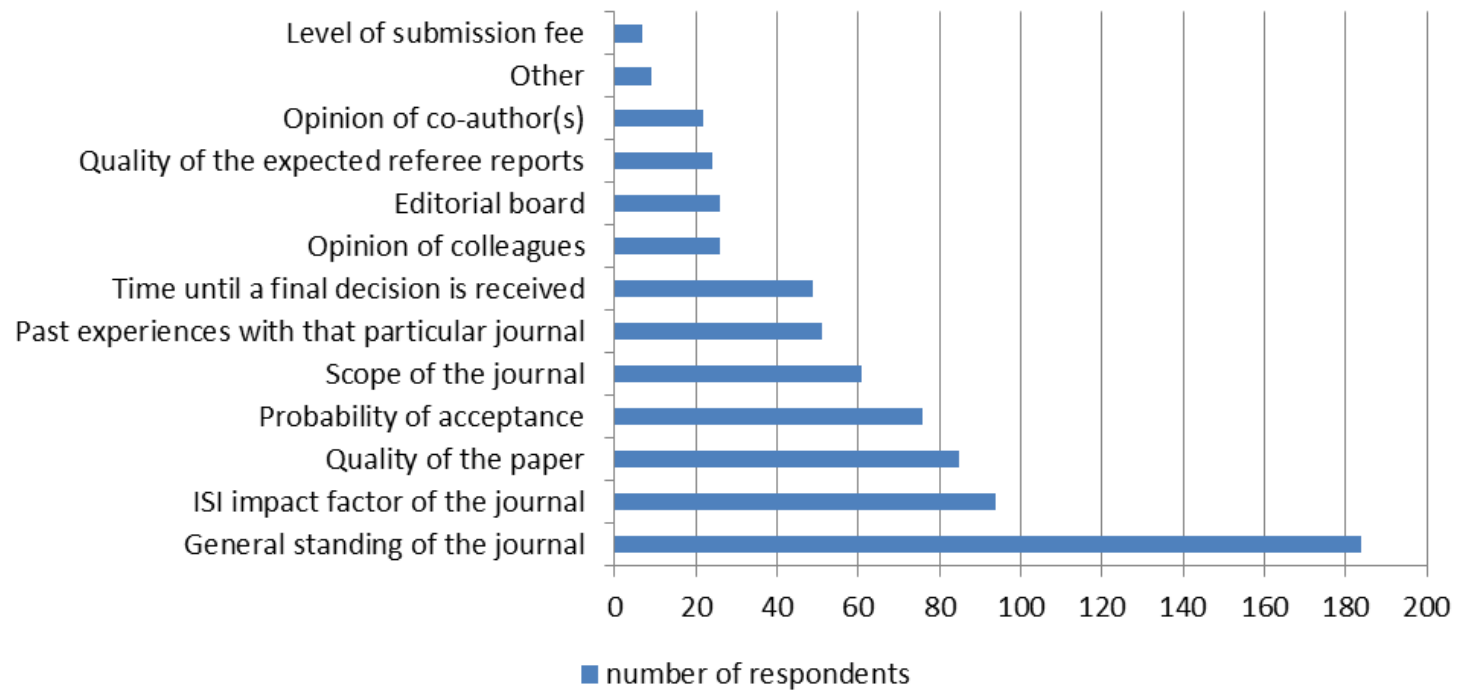

\subsection{Main effects}

We used a conditional logit model (see section 2.1) to estimate the coefficients of the factors explaining the probability that a particular journal variety was chosen by the respondents, The coefficients associated with the different journal characteristics were estimated using the statistical program STATA and are presented in Table 7 (definitions of variables can be found in Table 2). The coefficients for both alternative specific constants (ASC1 and ASC2) were positive and similar in size, which indicates that respondents generally preferred one of the included journal varieties over the back-up journal and that there is no effect on the estimated coefficient of the place (first or second) of the alternative in a choice set.

Table 7. Conditional logit estimation results (results in italics are not significant at the $\mathbf{5 \%}$ level).

\begin{tabular}{|l|llllll|}
\hline Choice & Coef. & $\begin{array}{l}\text { Robust } \\
\text { Err. }\end{array}$ & $\mathrm{Z}$ & $\mathrm{P}>\mathrm{z}$ & \multicolumn{2}{c|}{$[95 \%$ Conf. Interval] } \\
\hline Higheditor & .3819373 & .0972426 & 3.93 & 0.000 & .1913453 & .5725293 \\
\hline Medref & .1382777 & .1286743 & 1.07 & 0.283 & -.1139193 & .3904747 \\
Highref & .05283 & .1504094 & 0.35 & 0.725 & -.241967 & .3476271 \\
\hline Lowprobacc & -.1050774 & .1149858 & -0.91 & 0.361 & -.3304455 & .1202906 \\
Medprobacc & -.2147997 & .0953373 & -2.25 & 0.024 & -.4016574 & -.0279419 \\
\hline Lowimpact & .1305454 & .1509108 & 0.87 & 0.387 & -.1652343 & .4263251 \\
Highimpact & 1.011245 & .1619022 & 6.25 & 0.000 & .6939228 & 1.328568 \\
\hline
\end{tabular}




\begin{tabular}{|l|llllll|}
\hline Medstand & .9954841 & .1660113 & 6.00 & 0.000 & .6701079 & 1.32086 \\
Highstand & .7075058 & .1386888 & 5.10 & 0.000 & .4356807 & .9793309 \\
\hline Econscope & -.9511338 & .1391195 & -6.84 & 0.000 & -1.223803 & -.6784647 \\
Histscope & -.8759389 & .1378078 & -6.36 & 0.000 & -1.146037 & -.6058404 \\
\hline Time & -.0342077 & .0087523 & -3.91 & 0.000 & -.0513619 & -.0170535 \\
\hline ASC1 & 1.283072 & .2239288 & 5.73 & 0.000 & .8441797 & 1.721964 \\
\hline ASC2 & 1.504714 & .1677787 & 8.97 & 0.000 & 1.175874 & 1.833554 \\
\hline & Obs $=235$ clusters & & & & \\
& Pseudo R ${ }^{2}=0.2739$ & & & & \\
\hline
\end{tabular}

Three factors clearly dominated the submission preferences: the ISI impact factor of the journal, the journals' standing and its scope. In other words, researchers prefer their paper to be published in a journal with a high impact factor, a high standing and in a specialized journal reflecting the main scope of their research activities (i.e. in journals specialized in economic history). By and large, these results are as expected. To submit their work and keeping all other factors constant, researchers prefer:

- journals with highly regarded editors over journals with unknown editors.

- journals with an ISI impact factor over those with no impact factor.

- journals with higher ISI impact factors over those with lower impact factors.

- journals with a high or average standing among peers over those with no standing.

- specialized journals with a scope in economic history over journals with a specific economic or historical scope.

- journals with a faster decision making process.

Table 8. Willingness-to-wait (WTW) estimates (results between brackets are not significant at the $5 \%$ level).

\begin{tabular}{|l|ccc|}
\hline & WTW (in months) & \multicolumn{2}{c|}{$95 \%$ confidence interval } \\
\hline Higheditor & 11.17 & 3.03 & 19.30 \\
\hline Medref & $(4.04)$ & -3.26 & 11.35 \\
Highref & $(1.54)$ & -7.23 & 10.32 \\
\hline Lowprobacc & $(-3.07)$ & -9.69 & 3.55 \\
Medprobacc & -6.28 & -12.85 & 0.29 \\
\hline Lowimpact & $(3.82)$ & -5.75 & 13.38 \\
Highimpact & 29.56 & 11.71 & 47.42 \\
\hline Medstand & 29.10 & 11.94 & 46.26 \\
Highstand & 20.68 & 10.75 & 30.61 \\
\hline Econscope & -27.80 & -44.86 & -10.75 \\
Histscope & -25.61 & -38.67 & -12.54 \\
\hline
\end{tabular}

For a more detailed analysis of the main effects of characteristics levels on the submission choices made by researchers, we calculated the willingness-to-wait (WTW) for each characteristics level using equation (4). The resulting estimates are presented in Table 8. The most important characteristics determining the authors' WTW are the standing of the journal, 
its impact factor and its scope. Recall that we measure how long researchers would be willing to wait for a chance of being published in a particular journal. Thus this willingness to wait can greatly exceed actual waiting times if a publication in a particular journal is perceived to be essential by the respondent. For instance, a researcher can get tenure, be promoted, increase his/her standing, or receive funding based on a particular (series of) publication(s). More specifically, authors want to wait longer for a decision from a journal with (average or high) standing than for a journal without standing. However, it is surprising that on average, authors are willing to wait 29 months longer when submitting a paper to a journal with average standing than for a journal with no standing, whereas this is only 21 months longer when submitting a paper to a journal with high standing (Table 8). A possible explanation for this discrepancy could be that the 'publish or perish' pressure is rather high. Two respondents described this problem as follows:

'In the United States and I think in some places in Europe junior professors are against the clock. ... For instance, sometimes you prefer to publish a paper that you know has no chance in a top journal in a back-up journal, just to get it quickly out of your way. For the extremely good paper you fight hard and try to place them in excellent journals, but for medium quality papers is where the tradeoffs between quality of the journal, timing, and standing among peers are more binding.'

'I am at an American university and I'll send my tenure file out in one year, which is part of the reason that the review time is so important to me at the moment. It won't be as significant in the future, but I would never want to wait 18 months for a decision, no matter how prestigious the journal.'

As for the chosen journal's impact factor, the respondents' WTW especially increases for a journal with an impact factor above one. For example, keeping all other factors constant, researchers are willing to wait 30 months longer for a journal with an ISI impact factor above one than for a journal without impact factor. Surprisingly we do not find a statistical difference between journals with a low impact factor (less than one) and those with no impact factor at all. One respondent described the importance of a journal's impact factor as follows:

'Unfortunately, in country $X$, things go down a blind-alley: impact factor or die. This is incredibly sad, stupid and narrow minded. But this is the game and if you don't play it you are out. Perhaps we need more historically oriented economics journals - there are too few.'

The negative estimates of the WTW for a journal with a purely economic or historical scope have to be interpreted relative to the reference category, a specialized journal in economic history. In other words, the respondents are willing to wait 28 months less for a journal in general economics and 26 months less for a journal in general history than for a specialized journal. Thus, respondents really want to publish in specialized journals. Two respondents gave extra information when asked about the scope of the journal they aim at: 
'When I consider the scope of a journal, I do so because I am attempting to target journals interested in the type of research that I do, not because I care what discipline the journal targets.'

I aim at journals in the scope of economic, business or financial history, as for economic journals my research is considered too old and too descriptive, and for purely history journals it is often too econom(etr)ic.'

Less influential, but still important are the quality of the editorial board and the probability of acceptance. The respondents are willing to wait 11 months longer when submitting a paper to a journal with highly regarded editors than to a journal with an unknown editorial board. We find no statistical difference between journals with average or high quality referee reports and those with low quality referee reports (Table 8). This result is rather counterintuitive since, if their paper is not accepted, researchers could presumably use comments provided by referees and editors to improve the quality of the text and increase the chances of getting the paper published. A possible reason for this finding might be the variable quality of referee reports within a journal. As one respondent put it:

'I don't think journals -and I edit one- have consistent reputations in the way you suggest. Some referees' reports are good, some bad, and even as an editor it is hard to know ex ante which you will get.'

Further, regarding the general probability of an article being accepted in a certain journal, the negative estimates of the WTW for a journal with a (low or) average probability of acceptance have to be interpreted against the reference category which is a journal with a high probability of acceptance. Researchers are willing to wait 6 months less for a journal with a probability of acceptance between 30 and $70 \%$ than for a journal with an acceptance rate above $70 \%$. This could again be partially explained by the high publication pressure.

\subsection{Interaction effects}

Thus far, we have reported the results of a choice model in which only the journal attributes were taken into account. However, the respondents' characteristics are also likely to affect their preferences and their WTW for editorial decisions. In this respect, our research extends previous approaches, by also investigating how the WTW for journal characteristics depends on the respondents' characteristics (both personal and work-related characteristics). We used interaction terms between journal characteristics and respondents' characteristics to test for the presence of heterogeneous preferences. Table 9 provides an overview of the observed differences in WTW for certain characteristics according to differences in respondents' characteristics. We only report results for those characteristics that are differently valued by the respondents (statistically significant at the $5 \%$ level). Interaction effects with a particular characteristic were jointly introduced in the main effects model (see Table 7) for relevant characteristics. 


\subsubsection{Personal interaction effects}

The WTWs for journal characteristics were not significantly different when comparing preferences along some particular dimensions. Specifically, gender does not influence preferences. Also, there is no difference in preferences for submitting a paper with respect to the past publication record nor the researcher's motivation for publishing in order to get funding. However, we did observe an effect on the WTW for journal characteristics with respect to age, the institution type, the continent of affiliation and the current employment situation.

Table 9. Differences in WTW (in months) for journal characteristics in interaction with respondents' characteristics

\begin{tabular}{|lcc|}
\hline WTW for a journal with ... & & \\
\hline & younger than 35 & not younger than 35 \\
a highly regarded editor & $/$ & $/$ \\
an economic scope & -14.52 & -33.12 \\
\hline & affiliated with a university & not affiliated with a \\
university \\
average quality referee reports & $/$ & $/$ \\
a high impact factor & 31.93 & 15.67 \\
high standing among peers & 23.35 & 6.35 \\
\hline & North American affiliation & non-North American \\
a low probability of acceptance & 6.27 & affiliation \\
a low impact factor & $/$ & -5.25 \\
\hline & temporary contract and & $/$ \\
an economic scope & actively seeking new position & Others \\
\end{tabular}

( / = not significant at the $5 \%$ level).

Considering the impact of age, the respondents prefer a journal within the scope of economic history (the reference group) above a journal with an economic scope. However, the respondents that are younger than 35 are less patient when waiting for a journal with an economic history scope than the respondents that are older (15 versus 33 months). Probably, the younger respondents feel the pressure to publish more clearly.

With regard to the institution type of affiliation, all respondents prefer a journal with a high impact factor and/or a high standing among peers above the reference journal. However, those affiliated with a university find a high impact factor and a high standing among peers more important (WTWs of 32 and 23 months) than the respondents not affiliated with a university (with WTWs of 16 and 6 months respectively) when compared to a journal with no impact factor and/or a low standing among peers.

We further observed some differences between North American affiliated researchers and non-North American affiliated researchers with regard to the manuscript submission decision. 
Surprisingly, the respondents with a North American affiliation are prepared to wait 11 months longer than the non-North American respondents for a journal with a low probability of acceptance (compared to a journal with a high probability of acceptance).

Lastly, the respondents who are currently in a temporary position and are actively seeking for a new position within the next two years are still willing to wait some 15 months extra for a paper in a journal with an economic, business and/or financial history scope compared to a journal with an economic scope, but they will more quickly opt for a journal with an economic scope than the other respondents who are willing to wait an additional 30 months to get their paper published in an economic history journal. Researchers who are actively seeking a new position may have to show that some of their articles were recently published.

\subsubsection{Work-related interaction effects}

When dividing the group according to their research discipline (history versus economics), we found some interesting differences in WTW according to differences in the respondents' characteristics with regard to main research area, department of affiliation and obtained degree of education (PhD) (see Table 10). First, we looked at respondents with as main research area economic history versus the others and those with as main research area economics versus the others; second, we looked at the difference between those working in a history department versus the others and those working in an economics department versus the others. Lastly, we looked at those with a $P h D$ in history versus those with no $\mathrm{PhD}$ in history and those with a $\mathrm{PhD}$ in economics versus the respondents with no $\mathrm{PhD}$ in economics.

Table 10. Differences in WTW (in months) of the respondents for journal characteristics, according to the research discipline

\begin{tabular}{|lcc|}
\hline WTW for a journal with ... & \multicolumn{2}{c|}{ Main research area } \\
\hline & eco, bus and/or fin hist. & not eco, bus and/or fin hist. \\
high impact factor & $/$ & $/$ \\
economic scope & -35.37 & -17.63 \\
history scope & -30.74 & -18.73 \\
average quality referee reports & $/$ & $/$ \\
low probability of acceptance & $/$ & $/$ \\
average probability of acceptance & $/$ & not economics \\
& Economics & -0.03 \\
low impact factor & 47.43 & 23.26 \\
high impact factor & 85.59 & -31.75 \\
economic scope & 2.58 & $/$ \\
highly regarded editor & $/$ & $/$ \\
average quality referee reports & $/$ &
\end{tabular}




\begin{tabular}{|c|c|c|}
\hline high quality referee reports & 51.69 & -1.03 \\
\hline low probability of acceptance & l & l \\
\hline average probability of acceptance & l & / \\
\hline & \multicolumn{2}{|c|}{ Department of affiliation } \\
\hline & history department & not history dep \\
\hline economic scope & -41.46 & -24.27 \\
\hline history scope & -6.70 & -28.04 \\
\hline \multirow[t]{2}{*}{ high standing among peers } & l & 1 \\
\hline & economics department & not economics dep. \\
\hline high impact factor & 35.64 & 19.67 \\
\hline economic scope & / & l \\
\hline history scope & -31.73 & -16.29 \\
\hline average quality referee reports & I & / \\
\hline low probability of acceptance & I & / \\
\hline average probability of acceptance & l & / \\
\hline \multirow[t]{3}{*}{ high standing among peers } & l & l \\
\hline & \multicolumn{2}{|c|}{ obtained degree of education (PhD) } \\
\hline & history $\mathrm{PhD}$ & no history $\mathrm{PhD}$ \\
\hline high impact factor & 9.69 & 46.76 \\
\hline economic scope & / & / \\
\hline history scope & -5.28 & -41.31 \\
\hline average quality referee reports & / & / \\
\hline low probability of acceptance & l & / \\
\hline average probability of acceptance & / & / \\
\hline \multirow[t]{2}{*}{ high standing among peers } & 16.34 & 23.91 \\
\hline & economics PhD & no econ. $\mathrm{PhD}$ \\
\hline high impact factor & 44.32 & 31.33 \\
\hline economic scope & -15.10 & -43.67 \\
\hline history scope & -39.99 & -24.99 \\
\hline average quality referee reports & / & / \\
\hline low probability of acceptance & / & l \\
\hline average probability of acceptance & -1.17 & -11.38 \\
\hline high standing among peers & / & / \\
\hline
\end{tabular}

We found some clear differences between the respondents linked to 'history' and those linked to 'economics' with regard to the journal's impact factor, its scope, the quality of its referee reports, its standing and the probability of acceptance.

First, the respondents linked to economics find journals with impact factors more important than those working in history. For instance, although both groups prefer a high impact factor over no impact factor (both groups are willing to wait much longer - 86 months and 23 months longer respectively - for a journal with an impact factor compared to a journal without impact factor), the respondents working mainly in economics are prepared to wait 
approximately 60 months longer for a journal with a high impact factor than those whose main research area is not economics. This clearly demonstrates how the value that researchers attach to certain kinds of publications - measured by their willingness to wait - can greatly exceed the actual waiting times. A similar conclusion can be made when looking at the department of affiliation and the degree in education. Second, with regard to the scope, and looking at the main field of research, the respondents with economic history as main research area prefer to publish their paper in a specialized field journal. If this is not possible, the respondents linked to purely 'economics' prefer an economics journal, and those linked to purely 'history' prefer a history journal. This finding is corroborated by results for the department of affiliation and the degree of education. Third, regarding the quality of the referee reports, the respondents whose main research area is economics find a high quality report more important (WTW was 52 months longer) than the reference group (including history scholars). Fourth, a high standing among peers seems to be more important for those without a PhD in history versus those with a $\mathrm{PhD}$ in history. Fifth, and lastly, an average probability of acceptance (compared to a high probability of acceptance) seems less important for those with an economics $\mathrm{PhD}$ than those without an economics $\mathrm{PhD}$. The difference in publication preferences between history and economic departments is confirmed by Engels et al. (2012) for Belgian data. For instance, Engels et al. (2012) found that the distribution between publications recorded in the Web of Science (WoS) and other publications with academic standing (but not in WoS) differs greatly between fields: for example, in history only $15 \%$ of publications was registered in the WoS (so $85 \%$ was not), and in economics $55 \%$ was recorded in the WoS.

\subsubsection{The influence of personal characteristics versus work-related characteristics}

With respect to the effect of personal characteristic on the WTW, the differences in WTW range up to 32 (researchers affiliated with a university are prepared to wait a long time for a journal with a high impact factor). Focusing on work-related characteristics, we found that respondents are willing to wait much longer for a publication in their most preferred journal., The WTW ranges up to 86 months for these work-related characteristics (economists are prepared to wait a long time to get their paper published in a journal with a high impact factor). This shows that the most preferred journal and researchers' willingness-to-wait is influenced to a greater extent by the research discipline in which the respondents are active (history versus economics) than by their personal characteristics (e.g. the education or the type of $\mathrm{PhD}$ they obtained). 


\section{Comparing WTW estimates and actual waiting times}

When investigating the willingness to wait of authors to get an article published in a scientific journal, we used a choice experiment to look at the impact of particular journal attributes. Next we compared the calculated WTW's to waiting times for actual submissions in the field. We expect to find that the willingness to wait for particular journal attributes exceeds actual waiting times, since the WTW's act as a proxy of the value researchers attach to particular publications.

We start by looking at the delay from submission of the manuscript to acceptance (i.e. the socalled 'submission time' or 'review time'). Data on delay times are rarely available for existing journals. One reason may be the reluctance of publishers and editors to disclose the actual delays, as these are often relatively long. Other available data such as the journal circulation, the acceptance rate of submitted manuscripts, and the number of web downloads are also rarely made public (Björk and Öörni 2009; Björk and Solomon 2013). If available, information on the submission time is usually found in the actual pdfs of each individual article. Table 11 gives an overview of the top 20 of existing journals in the ISI field of 'History of Social Sciences' (which includes the domain of economic, business and/or financial history). These journals are ranked according to the ISI impact factors of 2011.

Most journals provide the date of publication (based on volume and issue number) and the date of the online publication of the accepted article (mentioned online). Only five journals give additional information on the date that the journal received the manuscript for revision, the date(s) that it received the revised submissions or the date that the final article was accepted for publication. Only two journals - The Economic History Review and Cliometrica - provide sufficient information to calculate the submission delay. The Economic History Review even provides information on the 'total delay time': i.e. the time span between date of submission of the manuscript for review and the publication date of the accepted article. Cliometrica mainly focuses on econometric approaches, while the Economic History Review publishes research from both historical and economic perspectives. Therefore, we investigated all articles that have been published in the Economic History Review in 2010 and 2011 (Figure 3). 
Table 11: Type of information on the 'total delay time' available in the top 20 journals in the field of the 'History of Social Sciences'

\begin{tabular}{|c|c|c|c|c|c|c|c|c|}
\hline \multirow[t]{2}{*}{ \# } & \multirow[t]{2}{*}{ Journal } & \multirow{2}{*}{$\begin{array}{c}2011 \\
\text { IF }\end{array}$} & \multirow{2}{*}{$\begin{array}{l}\text { 'total delay } \\
\text { time' }\end{array}$} & \multicolumn{5}{|c|}{ Type of information available: date of } \\
\hline & & & & submission & $\begin{array}{l}\text { revised } \\
\text { submission(s) }\end{array}$ & acceptance & $\begin{array}{l}\text { online } \\
\text { publication }\end{array}$ & $\begin{array}{l}\text { publication } \\
\text { (issue }+ \\
\text { volume no.) }\end{array}$ \\
\hline 1 & The Journal of Economic History & 1.015 & no & & & & $\mathrm{x}$ & $\mathrm{x}$ \\
\hline 2 & Explorations in Economic History & 0.935 & yes & $\mathrm{x}$ & & & $\mathrm{x}$ & $\mathrm{x}$ \\
\hline 3 & Journal of Historical Geography & 0.817 & no & & & & & $\mathrm{x}$ \\
\hline 4 & $\begin{array}{l}\text { Journal of the History of the } \\
\text { Behavioral Sciences }\end{array}$ & 0.793 & no & & & & $\mathrm{x}$ & $\mathrm{x}$ \\
\hline 5 & Economic History Review & 0.781 & yes & $\mathrm{x}$ & $\mathrm{x}$ & $\mathrm{x}$ & $\mathrm{x}$ & $\mathrm{x}$ \\
\hline 6 & $\begin{array}{l}\text { European Review of Economic } \\
\text { History }\end{array}$ & 0.774 & no & & & & $\mathrm{x}$ & $\mathrm{x}$ \\
\hline 7 & History of the Human Sciences & 0.621 & no & & & & $\mathrm{x}$ & $\mathrm{x}$ \\
\hline 8 & Libraries \& the Cultural Record & 0.571 & no & & & & & $\mathrm{x}$ \\
\hline 9 & Journal of Family History & 0.5 & no & & & $\mathrm{x}$ & $\mathrm{x}$ & $\mathrm{x}$ \\
\hline 10 & Social Science History & 0.485 & no & & & & & $\mathrm{x}$ \\
\hline 11 & Cliometrica & 0.48 & yes & $\mathrm{x}$ & & $\mathrm{x}$ & $\mathrm{x}$ & $\mathrm{x}$ \\
\hline 12 & History of Education & 0.462 & yes & $\mathrm{x}$ & $\mathrm{x}$ & & & $\mathrm{x}$ \\
\hline 13 & Business History Review & 0.444 & no & & & & & $\mathrm{x}$ \\
\hline 14 & $\begin{array}{l}\text { Journal of the History of Economic } \\
\text { Thought }\end{array}$ & 0.420 & no & & & & $\mathrm{x}$ & $\mathrm{x}$ \\
\hline 15 & The History of the Family & 0.410 & no & & & & $\mathrm{x}$ & $\mathrm{x}$ \\
\hline 16 & Paedagogica Historica & 0.391 & yes & $\mathrm{x}$ & $\mathrm{x}$ & & $\mathrm{x}$ & $\mathrm{x}$ \\
\hline 17 & Journal of Philosophy of Education & 0.371 & no & & & & & $\mathrm{x}$ \\
\hline 18 & Business History & 0.345 & no & & & & $\mathrm{x}$ & $\mathrm{x}$ \\
\hline 19 & Australian Economic History Review & 0.323 & no & & & & & $\mathrm{x}$ \\
\hline 20 & Enterprise \& Society & 0.312 & no & & & & $\mathrm{x}$ & $\mathrm{x}$ \\
\hline
\end{tabular}


Figure 3: Total delay time of all articles published in The Economic History Review (2010 and 2011)

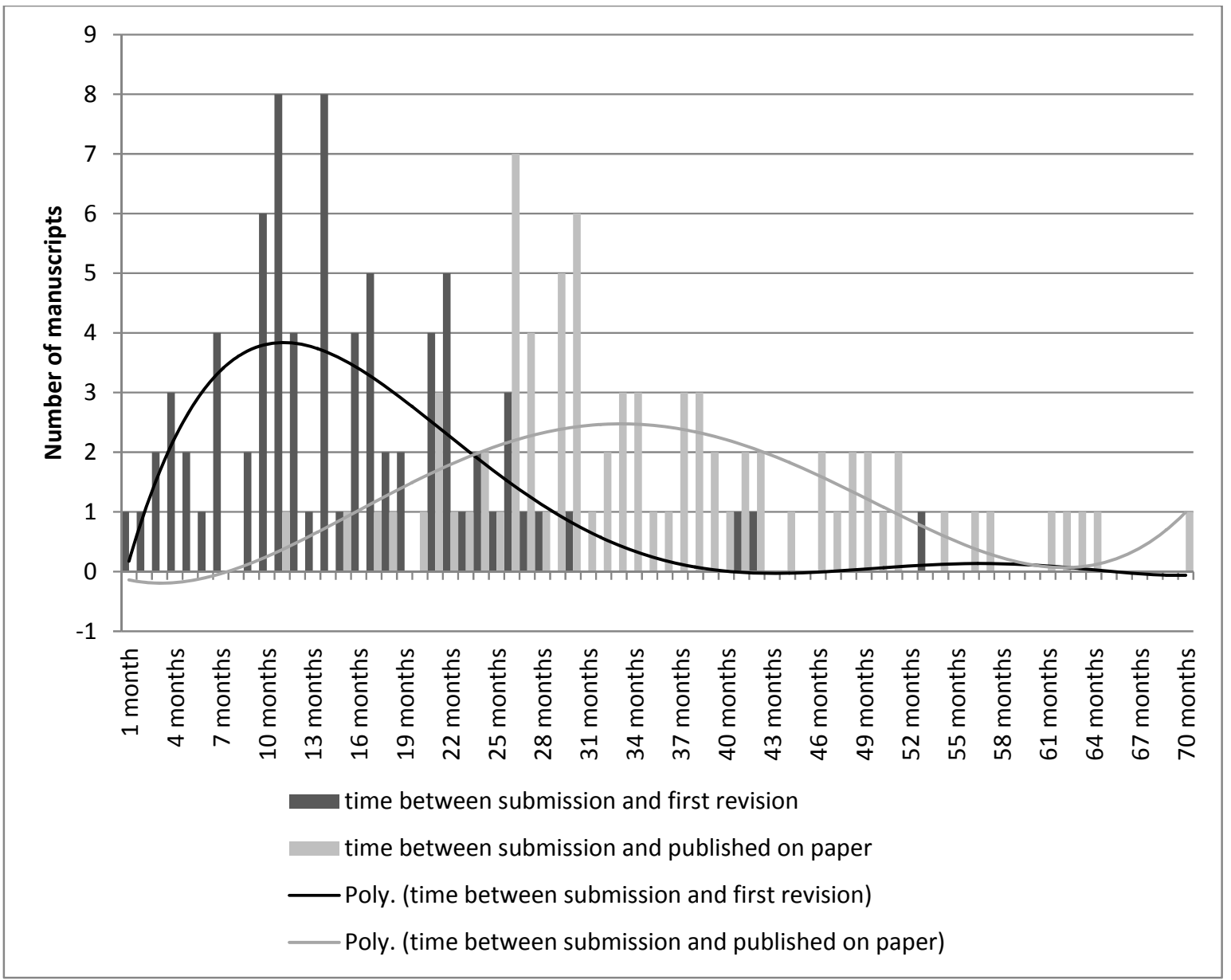

According to the information found for all 80 articles published in 2010 and 2011, the time span between submission of the paper and first revision was on average 15.63 months. The time span between submission and acceptance in this journal was on average 18.94 months (or 1.5 years) and the time between submission and paper publication amounts to 35.44 months (or almost 3 years) on average. One article was already accepted for publication after 3 months (published on paper after 11 months), another was only accepted after 56 months (published on paper after 70 months).

These delays are similar to those found in other studies: Luwel and Moed (1998) studied publication delays (time between submission and publication) in the science field and found average delays of 3 to 17 months in 1992 with the longest in the field of mathematics and technical sciences. Ellison (2002) found an average submission time of 16.5 months in 1999 for a selection of 25 journals in economics and related fields. Kling and Swygart-Hobaugh (2002) looked at three natural science journals and three social science journals between 
1970/1980 and 2000. They found decreasing publication delays over time in chemistry and physics journals, falling from 6.5 to 5.8 months; but increasing publication delays in the management, economics and psychological journals, rising from 9.0 to 23.8 months on average. Amat (2008) found publication delays ranging from 6.2 to 17.2 months in the field of food science. According to Björk and Solomon (2013), who studied average publication delays in 2700 articles published in 135 journals, sampled from the Scopus citation index, the waiting times between submission and publication were longest in the field of business and economics with an average time span between submission and acceptance of 10.75 months.

Thus, the WTW's we observed are different from the actual waiting times depending on the journal characteristics under consideration. On the one hand, we see that the WTW's for a journal with an impact factor, for a journal with high standing, or for a On the other hand, the WTW's for a journal with higher quality referee reports or for a journal with a higher acceptance probability are clearly lower than actual waiting times. Respondents seem to take into account that a detailed review of a manuscript requires a certain amount of time since quality takes time. Lastly, the WTW for a journal with a highly regarded editorial board is comparable to actual waiting times. In conclusion, the very high willingness to wait for publications in journals with a high impact factor and/or high standing clearly illustrates the 'publish or perish' pressure in academics. Often junior researchers need at least one top publication to get tenure. Such a high potential payoff can explain their willingness to wait as was illustrated by the previously discussed quotes. specialized journal respectively are considerably higher than actual waiting times on average. The interaction effects estimated in section 3.4 indicate that this pressure is significantly higher in the field (and department) of economics than in the field (and department) of history and economic history. Moreover, delay times do not remain constant, but tend to increase over time. This change in the length of the publication process has had a significant influence on the evaluation of (junior) faculty. In this respect, the "publish or perish" pressure is even increasing over time. The increasing delay times also influenced the number of articles per issue (less) and the number of pages per article (more) (Ellison 2002). Hence, there is a substantial increase in the competition between authors for space in the top journals.

\section{Conclusion}

In this work, we used a discrete choice experiment to determine the willingness-to-wait (WTW) in the context of journal submissions in the field of economic, business and/or financial history. We did not only look at the main effects of the different journal characteristics on the willingness-to-wait for a publication, but also at interaction effects with 
respondent characteristics. This allows us to estimate the different values researchers attach to publications with particular characteristics in this field.

Researchers' decisions regarding manuscript submissions were mainly dependent on journal characteristics. Authors were prepared to wait longer for a decision from a journal with standing and for an editorial decision for a journal with an ISI impact factor above one. Furthermore, the respondents preferred to publish in a specialized economic history journal and they preferred to submit a manuscript to a journal with highly regarded editors. Interaction effects originating from the respondents' characteristics with the WTW were highlighted as well. We found no differences in preferences for submitting a paper with respect to gender or past publication record of the researcher, nor with respect to the researcher's motivation for publishing. The most significant effect came from the respondent characteristics regarding the institution type with which they were affiliated. Researchers with a $\mathrm{PhD}$ in one type of discipline, working at a department of the other discipline, will have to significantly change their research and publication behavior in order to obtain tenure. In this respect, working in an interdisciplinary field clearly comes at a cost.

We note that the results of our investigations only apply to researchers active in the field of economic, business and/or financial history, or with a least some interest in this field (as shown by the fact that they published in the main journals of the field and/or attended some of the big conferences in the field). Thus, it would be interesting for future research to investigate whether our findings could be generalized to other (interdisciplinary) fields.

Finally, stated choice experiments are a useful tool when analyzing a wide variety of decision processes. These experiments could, for instance, be used to investigate the relative importance of factors influencing the decision to collaborate with a particular type of researcher (gender, rank, national or international) or research institution. They could also help in identifying classes of researchers that show similar collaborative behavior. Moreover, choice experiments could help in analyzing decisions to fund particular projects or to hire particular researchers. Further, they could also be useful in comparing authors' citation behavior: such as studying the relative importance of different articles' characteristics (such as familiarity with the authors, standing of the journal, time of publication, content fit, innovativeness, etc.) in the decision to cite a particular source in a text. Finally, choice experiments can be used to analyze the editors' decision in matching referees with submitted manuscripts, depending on characteristics, such as specialization, maturity and past experience with a particular referee. 


\section{Acknowledgments}

We thank all colleagues who took part in the survey for the time they invested in our research.

Moreover, we thank Alexander Genoe, Mathias Genoe, Geert Poelmans and Ronald Rousseau for their research assistance as well as the anonymous reviewers for useful comments. 


\section{References}

Abt, H.A. (1987). Are papers by well-known astronomers accepted for publication more readily than other papers? Publications of the Astronomical Society of the Pacific, 99, 439-41.

Alberini, A., Longo, A., \& Veronesi, M. (2006). Basic statistical models for stated choice studies. In Kanninen, B.J. (ed.), Valuing environmental amenities using Stated choice studies, 203-27. New York: Springer-Verlag.

Amat, C.B. (2008). Editorial and publication delay of papers submitted to 14 Selected Food Research Journals. Influence of online posting. Scientometrics, 74(3), 379.

Amaya-Amaya, M., Gerard, K., \& Ryan, M. (2008). Discrete choice experiments in a nutshell. In M. Ryan, K. Gerard \& M. Amaya-Amaya (eds.), Using discrete choice experiments to value health and health care, 13-46, New York: Springer.

Becher, T. (1994). The significance of disciplinary differences. Studies in Higher Education, 19(2), $151-61$.

Björk, B.-C. \& Öörni, A. (2009). A method for comparing scholarly journals as service providers to authors. Serials Review, 35, 62-69.

Björk, B.-C. \& Solomon, D. (2013). The publishing delay in scholarly peer-reviewed journals. Journal of Informetrics, 7, 914-923.

Björk, B.-C., \& Holmström, J. (2006). Benchmarking scientific journals from the submitting author's viewpoint. Learned Publishing, 19(2), 147-55.

Cheung, C. (2010). Audience matters: A study of how authors select educational journals. The AsiaPacific Education Researcher, 17.

Christie, M., Warren, J., Hanley, N., Murphy, K., Wright, R., Hyde T., \& Lyons, N. (2004). Developing measures for valuing changes in biodiversity: Final report. Peterborough, UK: Joint Nature Conservation Committee.

Conley, J.P., Crucinni, M.J., Driskill, R.A. \& Onder, A.S. (2011). Incentives and the effects of publication lags on life cycle research productivity in economics. Department of Economics, Vanderbilt University, Nashville, working paper, no. 11-w22, November 2011.

Day, B., Bateman, I.J., Carson, R.T., Dupont, D., Louviere, J.J., Morimoto, S., Scarpa, R. \& Wang, P. (2012). Ordering effects and choice set awareness in repeat-response stated preference studies. Journal of Environmental Economics and Management, 63(1), 73-91.

de Bekker-Grob, E.W., Hol, L., Donkers, B., van Dam, L., Habbema, J.D.F., van Leerdam, M.E., et al. (2010). Labeled versus unlabeled discrete choice experiments in health economics: An application to colorectal cancer screening. Value in Health, 13, 315-323.

Desjardins, Y. (2011). The work continues. Chronica Horticulturae, 51(1), 3-4.

Egghe, L. \& Rousseau, R. (2000). The influence of publication delays on the observed aging distribution of scientific literature. Journal of the American Society for Information Science, 51(2), $158-65$

Ellison, G. (2002). The Economic slowdown of the Economics Publishing Process. Journal of Political Economy, 110(5), 947-993.

Engels, T., Ossenblok, T. \& Spruyt, E. (2012). Changing publication patterns in the Social Sciences and Humanities, 2000-2009. Scientometrics, 93(2), 373-390.Frank, E. (1994). Authors' criteria for selecting journals. Journal of the American Medical Association, 272, 163-164.

Gordon, M.D. (1984). How authors select journals: A test of reward maximization models of submission behavior. Social Studies of Science, 14, 27-43.

Hanley, N., Mourato, S. \& Wright, R.E. (2001). Choice modeling approaches: A superior alternative for environmental valuation? Journal of Economic Surveys, 15(3), 435-62.

Hanley, N., Wright, R.E. \& Koop G. (2002). Modelling recreation demand using choice experiments: Climbing in Scotland. Environmental \& Resource Economics, 22(3), 449-66. 
Hicks. D. (2004). The four literatures of social science. In Moed, H.F., W. Glänzel, \& U. Schmoch (eds.) Handbook of quantitative science and technology research, 473-95. Dordrecht, The Netherlands: Kluwer.

Kling, R. \& Swygart-Hobaugh, A.J. (2002). The internet and the velocity of scholarly journal publishing. Working paper No. WP-02-12, Bloomington, IN: Rob Kling Center for Social Informatics, School of Library and Information Science, Indiana University.

Knight, L.V., Steinbach, T.A., Levy, Y. (2008). Selecting an appropriate publication outlet: a comprehensive model of journal selection criteria for researchers in a broad range of academic disciplines. International Journal of Doctoral Studies, 3, 59-79.

Kwak, S.-Y., Yoo, S.-H. \& Kwak, S.-J. (2010). Valuing energy-saving measures in residential buildings: A choice experiment study. Energy Policy, 38(1), 673-77.

Leyman, A., Vandevelde, K., Van Rossem, R. \& Groenvynck, H. (2011). Senior onderzoekers aan het woord. [Senior researchers' opinions]. Ghent, Belgium: Human Researchers in Research.

Leyman, A., Vandevelde, K., Van Rossem, R. \& Groenvynck, H. (2011). Senior onderzoekers aan het woord. Gent: Human Researchers in Research $\left(\mathrm{HR}^{2}\right)$.

List, J.A. \& Shogren, J.F. (1999). Price information and bidding behavior in repeated second - price auctions. American Journal of Agricultural Economics, 81, 942-949

Louviere, J.J. \& Hensher, D.A. (1982). On the design and analysis of simulated choice or allocation experiments in travel choice modeling. Transportation Research Record, 890, 11-17.

Louviere, J.J. \& Woodworth, G. (1983). Design and analysis of stimulated choice experiments or allocation experiments: An approach based on aggregate data. Journal of Marketing Research, 20, 350-67.

Louviere, J.J., Hensher, D.A. \& Swait, J.D. (2000). Stated choice methods: Analysis and application. New York: Cambridge University Press.

Luukkonen, T. (1992). Is scientists' publishing behavior reward seeking? Scientometrics, 24, 297-319.

Luwel, M. \& Moed, H.F. (1998). Publication delays in the science field and their relationship to the ageing of scientific literature. Scientometrics, 41(1-2), 29-40.

Moed, H.F. (2005). Citation Analysis in Research Evaluation. Dordrecht (the Netherlands): Springer. ISBN: 1-4020-3713-9.

Nicholas, D., Jamali, H.R. \& Rowlands, I. (2006). On the tips of their tongues: authors and their views on scholarly publishing. Learned Publishing, 19(3), 193-203.

Pinski, G. \& Narin, F. (1976). Citation influence for journal aggregates of scientific publications: theory, with application to the literature of physics. Information Processing and Management, 12(5), 297-312.

Rousseau, R. (2002). Journal evaluation: technical and practical issues. Library Trends, 50(3), 418439.

Rousseau, S. \& Rousseau, R. (2012). Interactions between journal attributes and authors' willingness to wait for editorial decisions. Journal of the American Society for Information Science and Technology, 63(6), 1213-25.

Rousseau, S. \& Vranken, L. (2013). Green market expansion by reducing information asymmetries: evidence for labeled organic food products. Food Policy, 40, 31-43.

Saunders, M., Lewis, P., Thornhill, A., Booij, M. \& Verckens, J.P. (2011). Methoden en technieken van onderzoek. [Research methods and techniques]. Amsterdam, The Netherlands: Pearson Education Benelux.

Schaffner, A. (2002). Swiss Medical Weekly - one year at sea after major overhaul. Swiss Medical Weekly, 132(3), 3.

Søreide, K., \& Winter, D.C. (2010). Global survey of factors influencing choice of surgical journal for manuscript submission. Surgery, 147(4), 475-80. 
Stock, W.G. (2009). The inflation of impact factors of scientific journals. ChemPhysChem, 10, 21932196.

Street, D.J., Burgess, L. \& Louviere, J.J. (2005). Quick and easy choice sets: Constructing optimal and nearly optimal stated choice experiments. International Journal of Research in Marketing, 22, 45970.

Thompson, P.J. (2007). How to choose the right journal for your manuscript. Chest, 132, 1073-76.

Waltman, L., van Eck, N.J., van Leeuwen, T.N., Visser, M.S. \& van Raan, A.F.J. (2011). Towards a new crown indicator: Some theoretical considerations. Journal of Informetrics, 5(1), 37-47.

Weingart, P. (2005). Impact of bibliometrics upon the science system: Inadvertent consequences? Scientometrics, 62(1), 117- 131

Yu, G., Yu, D. \& Li, Y. (2004). The universal expression of periodical average publication delay at steady state. Scientometrics, 60(2), 121-29.

Ziobrowski, A.J. \& Gibler, K.M. (2000). Factors academic real estate authors consider when choosing where to submit a manuscript for publication. Journal of Real Estate Practice and Education, 3, 4354. 